\title{
RESPONSABILIDADE SOCIAL DAS EMPRESAS E SUA RELEVÂNCIA PARA A EVOLUÇÃO SOCIAL NA PERSPECTIVA DA REALIDADE BRASILEIRA
}

\author{
Francisco Cardozo Oliveira ${ }^{1}$ \\ Fernanda Pereira Macedo Guimarães ${ }^{2}$
}

\section{RESUMO}

$\mathrm{O}$ artigo analisa a importância das ações de responsabilidade social das empresas para a evolução social, considerada a realidade brasileira. Inicia-se pela análise das práticas de responsabilidade social das empresas que, em determinado momento econômico, exigiram definição conceitual e precisão de efeitos jurídicos. Na sequência a análise evolui para identificar a natureza da obrigação que envolve as ações de responsabilidade social das empresas. No final, a análise trata da relevância das ações de responsabilidade social para a evolução da sociedade identificada nas possibilidades abertas de ampliação de liberdade social em termos de superação de desigualdades na realidade brasileira.

Palavras-chave: Responsabilidade social; obrigação; regulamentação; atividade empresarial; evolução social.

\section{SOCIAL RESPONSIBILITY OF THE COMPANIES AND ITS RELEVANCE FOR SOCIAL EVOLUTION IN THE PERSPECTIVE OF BRAZILIAN REALITY}

\begin{abstract}
The article analyzes the importance of company social responsibility actions for social evolution, considered the Brazilian reality. It begins with the analysis of the practices of social responsibility of companies that, at a given economic moment, demanded conceptual definition and precision of legal effects. Following the analysis evolves to identify the nature of the obligation that involves the actions of company social responsibility. In the end, the analysis addresses the relevance of social responsibility actions to the social evolution identified in the open possibilities of expanding social freedom in terms of overcoming inequalities in the Brazilian reality.
\end{abstract}

Keywords: Social responsibility; obligation; regulation; business activity; social evolution.

\footnotetext{
${ }^{1}$ Pós doutor pela UFSC, Doutor em Direito pela UFPR, Professor do Mestrado do UNICURITIBA e Juiz de Direito no Tribunal de Justiça do Paraná

${ }^{2}$ Mestranda em Direito no UNICURITIBA. Especialista em Direito da Economia e da Empresa pela FGV (MBA). Advogada em Curitiba.
} 


\section{INTRODUÇÃO}

A configuração atual do capitalismo exigiu das empresas um compromisso mais estreito com o contexto da realidade social em que desenvolvida a atividade empresarial. $\mathrm{O}$ instituto da responsabilidade social das empresas condensa um conjunto de atividades que, embora não assuma a feição estrita de vinculação legal, acaba por conformar a atividade empresarial com reflexos sociais e jurídicos, capazes de influenciar os rumos da evolução social.

As ações de responsabilidade social contemplam uma dinâmica de preservação da imagem da empresa e de seus produtos na realidade social em que ela está inserida. Invariavelmente, as ações de responsabilidade social envolvem a preservação do meio ambiente, financiamento de atividades de proteção e de promoção social da pessoa, melhoria de vida de trabalhadores e comunidades, difusão e promoção da cultura e até o engajamento em políticas públicas em parceria com organismos estatais.

Em face do atual contexto socioeconômico, propõe-se como problema analisar a relevância da responsabilidade social das empresas para a evolução social, considerada a realidade brasileira.

Em torno desse problema articulam-se três objetivos definidos i) pela necessidade de especificar a concepção de responsabilidade social empresarial e seus efeitos jurídicos, ii) pela configuração das ações de responsabilidade social das empresas e, finalmente, iii) pela mensuração dos efeitos das ações de responsabilidade social das empresas na evolução da vida social, em especial na realidade brasileira de marcantes assimetrias e desigualdades.

Os objetivos propostos se desdobram na análise em dois capítulos que devem permitir sustentar uma conclusão plausível acerca do alcance e da relevância das ações de responsabilidade social das empresas, tendo-se em conta, obviamente, o quanto elas estão comprometidas com os fundamentos do ordenamento jurídico e a evolução social.

Em termos de método, adota-se uma perspectiva crítica, em que o método não é tomado de modo apriorístico, mas se desenvolve na medida em que a análise ganha sentido apoiada em fontes bibliográficas e documentais. 


\section{RECONSTRUÇÃO HISTÓRICA DO CONCEITO DE RESPONSABILIDADE SOCIAL DAS EMPRESAS}

O paradigma reconstrutivo, que se apoia no pensamento de Hegel, coloca ênfase nos desdobramentos da vida em sociedade e procura enfatizar o compromisso da evolução social com os horizontes estabelecidos para o desenvolvimento da socialidade. Trata-se, portanto, de verificar o quanto as ações sociais dos indivíduos e das empresas continuam guiadas, ao longo do tempo histórico, por aqueles valores morais, jurídicos e econômicos norteadores da busca pela consolidação de uma determinada vida em sociedade. Em relação à análise da responsabilidade social das empresas, trata-se de estabelecer a correlação entre os pressupostos orientadores dessas ações e sua conexão com o desenvolvimento da sociedade.

$\mathrm{Na}$ configuração histórica da responsabilidade social das empresas observa-se a passagem de uma prática consolidada nos mercados para uma preocupação conceitual e jurídica.

Resulta necessário, desse modo, analisar o percurso das ações de responsabilidade social das empresas na passagem da prática ao conceito, no contexto de reconfiguração da história da economia capitalista e seus reflexos jurídicos.

\subsection{A busca de uma prática de responsabilidade social das empresas}

A prática de ações de responsabilidade social por parte das empresas parece emergir no momento em que, com a consolidação da economia capitalista, na virada do Século XIX para o Século XX, percebeu-se dois efeitos sociais e econômicos complementares e, ao mesmo tempo, paradoxais: enquanto a atividade empresarial se revela capaz de produzir excedentes de riquezas e de lucros, acumulam-se em torno dela desigualdades sociais e assimetrias; mas o que se revela mais incisivo é a percepção de que o tempo de geração de riquezas, decorrente dos desdobramentos da atividade mercantil, pode não ser suficiente para inibir os efeitos de desigualdades crescentes, de modo que, para evitar riscos sociais e econômicos, se mostra necessário atuar para reduzir a pobreza e a exclusão social.

A prática de responsabilidade social já se fazia presente no cenário das organizações desde o século XIX, mas o início efetivo nos EUA se dá a partir de 1919, em torno da decisão do caso Dodge versus Ford. Henry Ford, presidente e acionista majoritário da Ford, contrariou os interesses dos demais acionistas. Alegando objetivos sociais, ele defendia a retenção de uma parte dos dividendos, que reverteriam para uma série de ações, como investimentos na produção e aumentos de salários. No entanto, a sentença foi favorável a Dodge, sob o entendimento dos 
tribunais de que a organização existia para beneficiar os acionistas e, portanto, o lucro não poderia ser utilizado para outros fins. Nesse caso, o investimento em filantropia e na imagem da organização empresarial só poderia ser feito se beneficiasse o lucro dos acionistas.

Outro caso, na década de 1950, que também instigou o debate a respeito da ética e da responsabilidade social foi o que envolveu a companhia americana A. P. Smith Manufacturing versus Barlow. Neste caso, diferentemente do primeiro, a decisão foi favorável à doação de recursos a uma universidade e contrariou interesses dos acionistas (MORCELLI, 2016. p. 16).

Em 1953, A. P. Smith Manufacturing Company versus seus acionistas trouxe novamente a discussão sobre a responsabilidade da empresa com a sociedade. Neste outro caso contestou-se a doação de recursos financeiros à Universidade de Princeton. Como resultado deste litígio, surgiu a Lei da Filantropia Corporativa regulando o modo como as empresas poderiam promover o desenvolvimento social.

Em um contexto mais contemporâneo, caracterizado pelo início da preocupação com diversos problemas sociais e ambientais, o bisneto de Henry Ford, Argila Ford Jr, então presidente da Ford, recebeu o apoio dos acionistas e dos stakeholders ao trazer novamente a importância dos negócios de sua empresa como um serviço para a sociedade e a ideia de tornar o mundo um lugar melhor para todos (MORCELLI, 2016. p. 16).

No Brasil, a preocupação com a responsabilidade social das empresas surgiu no decorrer de consolidação da economia neoliberal, contexto marcado por inúmeras ameaças e problemas sociais, como desigualdade, corrupção e alta taxa de desemprego.

A preocupação com responsabilidade social no Brasil, a partir da década de 1960, teve protagonismo nas ações de entidades religiosas ligadas a dirigentes empresariais como, por exemplo, a Associação de Dirigentes Cristãos de Empresas do Brasil (ADCE), que assimilou a questão social como um compromisso estratégico, no qual a empresa assumia responsabilidades, inserido na gestão de negócios. Esse protagonismo se justifica dado que no Brasil as entidades religiosas das mais diversas orientações de credo sempre dedicaram especial atenção à ajuda de pessoas atingidas pela miséria e pelos infortúnios de catástrofes e doenças. Estimulou-se a consciência dos gestores em relação à responsabilidade social que levou as empresas a iniciarem envolvimento com as questões sociais (MORCELLI, 2016, p. 17).

Na década de 1970 o valor das ações empresariais para a sociedade tornou-se extremamente importante, o que levou a preocupação de como e quando a empresa deveria responder por obrigações sociais, consolidando o valor da ética empresarial.

A responsabilidade social empresarial voltou a ser debatida no Brasil na década de 1980, com o fim da ditadura militar e da repressão política, quando se verifica uma explosão de 
organizações civis. O exercício da cidadania, até então reprimido, ganhou novo impulso mediante ações da sociedade civil organizada.

Na década de 1990, com uma maior participação das pessoas na vida em sociedade, aumentou a discussão sobre ética e moral nas empresas, o que contribuiu de modo significativo para a conceituação de responsabilidade social.

Em 1993, o sociólogo Herbert de Souza, o Betinho, lançou a Campanha Nacional da Ação da Cidadania contra a Fome, a Miséria e pela Vida, com o apoio do Pensamento Nacional das Bases Empresariais (PNBE), que constitui o marco da aproximação dos empresários com as ações sociais. Em 1997, segundo mencionam Mateus Eduardo Siqueira Nunes Bertoncini e Ane Elize Deonara Muller, Betinho lançou um modelo de Balanço Social (2012, p. 465-485) e, em parceria com a Gazeta Mercantil, criou o selo correspondente, estimulando as empresas na divulgação de seus resultados em participação social.

Em 1998, o empresário Oded Grajew criou o Instituto Ethos de Empresas e Responsabilidade Social, que se tornou referência e serviu e ponte entre empresários e causas sociais. Seu objetivo é disseminar a prática da responsabilidade social empresarial por meio de publicações, experiências, programas e eventos para interessados nessa atividade.

A reconstrução histórica mostra que a atividade empresarial permanecia distante da busca de soluções para problemas sociais, restringindo-se ao compromisso de gerar empregos e pagar impostos, o que, diga-se de passagem, é intrínseco ao modelo de acumulação de capital da econômica capitalista. No entanto, esse compromisso, típico do modelo fordista de produção, perdeu sentido à medida que a tecnologia começou a retirar os alicerces daquilo que se acreditava ser uma vida digna (MORCELLI, 2016, p. 17).

No momento em que se tornou claro que era necessário estabelecer limites para o exercício da atividade empresarial, de modo a impedir a degradação irrecuperável do meio ambiente e de, ao mesmo tempo, reduzir o potencial de pobreza e desigualdade decorrente da acumulação de capital, ganha sentido uma normatividade inspirada na ética da responsabilidade social das empresas.

\subsection{O conceito de responsabilidade social das empresas}

A prática de responsabilidade social das empresas, surgida no contexto da pragmática da atividade empresarial, passou a exigir uma precisão conceitual, de modo a permitir formas de institucionalização, de controle e de regulação jurídica. 
O conceito de responsabilidade social incorpora uma eticidade balizadora das ações e das relações com os diversos segmentos com os quais as empresas interagem: acionistas, funcionários, consumidores, rede de fornecedores, meio ambiente, governo, mercado e comunidade. De certo modo, a eticidade que a responsabilidade social incorpora pode ser compreendida no contexto de relações de reconhecimento que, de acordo com Hegel, estruturam a evolução social da modernidade. Em Hegel a ideia de eticidade (Sittlichkeit) não se confunde com a de costume (Sitten) porque o ético para ele se constitui a partir dos desdobramento da vida da pessoa na relações com o outro em sociedade; a eticidade envolve uma compreensão pessoal da vida em sociedade e, ao mesmo tempo, o modo como se desenvolve a relação com os outros; em última análise, o que a ideia de eticidade encerra é a natureza mesma da vida do homem em sociedade (1982). No âmbito da responsabilidade social das empresas, tratar-se-ia de uma ética de compromisso com a constituição do social que repercute efeitos na vida concreta das pessoas em sociedade. A questão da normatividade, portanto, não envolve apenas o direito positivo; antes, engloba todo o sistema de normas que estrutura a evolução social. Desse modo, não pode ser negligenciado que as ações de responsabilidade social das empresas contemplam um potencial de normatividade e de reconhecimento do outro na vida em sociedade que se desdobrou na lógica de reestruturação das formas de acumulação de capital ao longo da história.

Ortová e Stanková salientam que a mudança da terminologia de responsabilidade social corporativa para responsabilidade social se torna comum a todas as organizações; ao mesmo tempo em que traz a possibilidade de que cada área, segmento ou organização crie sua própria compreensão de responsabilidade social (2011, p. 372).

A responsabilidade social das empresas diz respeito ao compromisso com a legalidade e com as necessidades da comunidade pensadas em termos de melhoria das condições de vida de todos. Como lembram Marcos Alves da Silva e Viviane Coelho de Séllos Knoerr, trata-se de compatibilizar a atividade empresarial com os fundamentos da Constituição brasileira de 1988 (2013, p, 435-453). Nesse sentido, Fabiane Lopes B. N. Bessa afirma que a responsabilidade social das empresas contempla um agir de acordo com o direito, com a função social da empresa e com os princípios de direito privado, considerado o contex to do interesse público envolvido $(2006,141)$. Não resta dúvida, portanto, que, observadas essas premissas, as ações de responsabilidade social das empresas estão integradas às finalidades de gestão da atividade empresarial. 
Fiel à pragmática da responsabilidade social da atividade empresarial, o Instituto Ethos elaborou um conceito de responsabilidade social atento à realidade social e econômica brasileira; diz o referido Instituto que a responsabilidade social das empresas é,

(...) a forma de gestão que se define pela relação ética e transparente da empresa com todos os públicos com os quais ela se relaciona e pelo estabelecimento de metas empresariais que impulsionem o desenvolvimento sustentável da sociedade, preservando recursos ambientais e culturais para as gerações futuras, respeitando a diversidade e promovendo a redução das desigualdades sociais. (ETHOS, 2016)

Para Carlos Aurélio M. Souza as ações de responsabilidade social compreendem diretrizes capazes de "promover o bem-estar dos funcionários, proporcionando seu aperfeiçoamento profissional e pessoal; proteger os recursos naturais locais; respeitar o direito dos consumidores e os direitos humanos em geral; enfim, a satisfação de necessidades fundamentais da coletividade" (2007, p. 50).

A fragmentação da sociedade contemporânea coloca uma série de demandas que o Estado não se mostra capaz de dar resposta, em face do compromisso com a manutenção das taxas de lucros nos mercados. Com a convicção de que as empresas são responsáveis por parte das mazelas sociais criou-se, paulatinamente, a ideia de que há uma expectativa por ações socialmente responsáveis; em outras palavras, espera-se que a empresa assuma a responsabilidade para com os interesses sociais de modo abrangente. É neste sentido que Mara Darcanchy sustenta que,

Destarte, a questão que se ressalta é que a identificação da empresa como ética e socialmente responsável não resulta somente da criação e/ou participação em grandiosos projetos sociais com autopromoção midiática, mas, sim, também de ações cotidianas de seus gestores, como a preocupação com o entorno, com a comunidade local onde a empresa está inserida; o tratamento digno concedido aos seus colaboradores através das políticas públicas de contratação do trabalho decente; o compromisso de não ter contato profissional com nenhum fornecedor que se utilize de mão de obra infantil, escrava ou de qualquer outra forma degradante; o cuidado com a sustentabilidade de seu meio de produção e com o meio ambiente; o pagamento dos impostos devidos e de salários justos sem discriminação de gênero ou de qualquer outra espécie; atitudes estas, entre outras, que demonstram um comprometimento muito maior do que as abordagens pontuais. Isto significa uma mudança de valores e comportamentos. (2011. p. 34)

Em linhas gerais, pode-se afirmar que o conceito de responsabilidade social envolve um compromisso ético com a promoção de melhores condições de vida para as pessoas diretamente envolvidas na atividade empresarial, bem como para com a preservação do meio 
ambiente e dos valores comunitários necessários ao desenvolvimento de uma vida digna que vale a pena ser vivida.

Nesse sentido, não é o caso de restringir as ações de responsabilidade social ao aumento de lucros das empresas como defendido, por exemplo, por Milton Friedman (2014), na medida em que a atual configuração do capitalismo contemporâneo, e de suas crises, a exemplo do que ocorreu em 2008, evidencia que a busca desenfreada por taxas de rentabilidade coloca em risco a própria atividade empresarial. A responsabilidade social das empresas não se restringe a potencializar lucros, inclusive mediante a socialização de prejuízos nos momentos de crises, via atuação do Estado. A questão a ser enfrentada, portanto, não é dar conta da oposição entre lucro e responsabilidade social, mas compatibilizar a configuração das ações de responsabilidade social das empresas com a evolução social, e nisso reside a complexidade do desafio para empresários e pesquisadores.

\section{CONFIGURAÇÃO DAS AÇÕES DE RESPONSABILIDADE SOCIAL DAS EMPRESAS E SEUS REFLEXOS JURÍDICOS E SOCIAIS}

$\mathrm{Na}$ medida em que as ações de responsabilidade social das empresas exigiram fundamentação conceitual, para dar conta de práticas que se revelaram necessárias aos desdobramentos da economia de mercado, ganhou relevo também a necessidade de precisar o alcance jurídico e social delas. Do ponto de vista jurídico, trata-se de verificar até que ponto as ações de responsabilidade social das empresas podem configurar uma espécie de obrigação de caráter vinculativo; por outro lado, do ponto de vista social, resulta necessário verificar o quanto as ações de responsabilidade social contribuem para alterar a realidade social e econômica, em especial no caso do Brasil.

\subsection{Ações de responsabilidade social das empresas e seus reflexos jurídicos}

A compreensão do alcance jurídico das ações de responsabilidade social das empresas exige considerar, em um primeiro momento, o sentido e os efeitos da noção de responsabilidade para, em um segundo momento, situar o seu desdobramento normativo no ordenamento jurídico.

A ideia de responsabilidade no direito civil, segundo Fernando Noronha, assume o sentido de direito a indenização em razão de prejuízos; assim, a responsabilidade tem uma 
conotação patrimonial, em que o devedor responde pelo pagamento de uma dívida, mediante o valor dos bens integrantes do seu patrimônio (2010, p. 152). Observa-se que, neste caso, o sentido de responsabilidade se conecta ao direito das obrigações; nessa direção, a responsabilidade social das empresas poderia ser enquadrada como uma espécie de obrigação que, todavia, não tem caráter juridicamente vinculante; e sem a vinculação decorrente de uma relação jurídica obrigacional, a responsabilidade social das empresas poderia ser admitida como espécie de obrigação natural em que, para sintetizar o que afirma Fernando Noronha, a prestação se realiza em favor de determinada pessoa, sem que ela possa exigi-la, ou seja, uma obrigação desprovida de ação (2010, p. 241). Uma vez compreendida a responsabilidade social das empresas como espécie de obrigação natural, tendo sido realizada a prestação, surgiria a pretensão de agir para manter os seus efeitos, em benefício da comunidade. Nesse sentido, as ações de responsabilidade social realizadas pelas empresas teriam reflexos jurídicos na medida em que incorporadas na realidade da vida das pessoas e no contexto de construção da socialidade.

No Brasil ainda não existe uma legislação específica reguladora da responsabilidade social das empresas. Em 1991, foi encaminhado ao Congresso Nacional um anteprojeto propondo a publicação do Balanço Social pelas empresas, porém, ele não foi aprovado. De todo modo, de uma perspectiva normativista, a preservação dos efeitos jurídicos das ações de responsabilidade social encontra fundamento nos princípios integrantes da ordem constitucional. Em torno dessa perspectiva Ligia Neves da Silva e Francisco Cardozo Oliveira sustentam que a responsabilidade social das empresas se insere na dinâmica de proteção do princípio da dignidade da pessoa humana, integrante da Constituição brasileira de 1988 (art. $1 .^{\circ}$, III), e pode ser compreendida entre as finalidades de função social do direito de propriedade empresarial e do contrato (2012, p. 83-88).

Por outro lado, de uma perspectiva de normatividade material, que leva em conta os desdobramentos da vida em sociedade, o caráter jurídico das ações de responsabilidade social das empresas decorre de um compromisso ético que encontra a sua positivação na Constituição brasileira de 1988 no princípio da solidariedade (art. 3. ${ }^{\circ}$, I); é nesse sentido que Ligia Neves da Silva e Francisco Cardozo Oliveira buscam suporte no pensamento de Hans Jonas para quem a definição de responsabilidade engloba o comprometimento social com a realização dos direitos humanos (p. 2012, p. 112). Com efeito, para Hans Jonas a responsabilidade tem uma componente inerente ao humano de modo que o valor que o "bem" da ação incorpora justifica uma reivindicação pelo dever-ser transformando-se em obrigação do agir na situação em que a pessoa dependa da livre escolha desse agir (2006, p. 102). Em sentido complementar a essa 
premissa pode ser invocado o pensamento de Amartya Sen que fala de uma humanidade compartilhada, que não tem lugar para divisões impenetráveis; diz ele que,

\begin{abstract}
(...) a principal esperança de harmonia no mundo contemporâneo se encontra na pluralidade de nossas identidades que se cruzam umas com as outras e agem contras as divisões rígidas em torno de uma linha única e endurecida de divisão impenetrável. Nossa humanidade compartilhada é desafiada brutalmente quando o confronto é unificado em um só suposto sistema dominante de classificação (...). A diversidade plural pode ser muito unificadora, de uma forma que um sistema único de divisões predominantes não é. (2010, p. 43)
\end{abstract}

Voltando a Hans Jonas, o que ele afirma é que as ações feitas em favor da pessoa, na medida em que considerada a responsabilidade como algo essencialmente humano, faz surgir uma obrigação que, em face da normatividade que lhe é característica, incorpora a exigibilidade e a possibilidade de defesa dela acaso necessário para a vida em sociedade. A responsabilidade social das empresas, desse modo, no dizer de José Edmilson de Souza Lima e Outro (2014)., contém um compromisso com o outro e, portanto, caminha na direção de superação do individualismo característico da modernidade.

Já não mais é mais o caso da defesa da acumulação de lucros que não considera os interesses da pessoa. Dá-se especial valor ao modo como este processo é desencadeado ao longo das relações de mercado, visando a humanização de toda cadeia produtiva, pois, em grande medida, resulta claro que a produção e a comercialização de bens e serviços não podem ser realizados sem que a vida em toda a sua extensão seja afetada. Conforme sustenta Alvin Toffler, a consequência dos processos de produção é, a propósito do modelo constitutivo e estrutural da sociedade moderna, a "centralização" (1992, p. 71). A especialização transformou a sociedade em formas de quantificação. Deve-ser dar relevância ao observado por Alvin Toffler quando enfatiza que "está começando a nos parecer que nossa ênfase obsessiva no detalhe quantitativo sem contexto, em medição cada vez mais detalhada de problemas cada vez menores, levou-nos a saber cada vez mais sobre cada vez menos.” (1992, p. 138).

Uma nova consciência passa a fazer parte da cadeia de relações sociais. Não seria o caso, portanto, de reduzir as ações de responsabilidade social das empresas a mero esforço para assegurar imagem nos mercado, ou dar suporte a um discurso de responsabilidade social, de modo a escamotear práticas danosas para a pessoa e o meio ambiente, no sentido do que comenta Patrícia Almeida Ashley (2005. p. 76-77).

Os perigos de destruição e catástrofes ecológicas são reais. Lentamente, a sociedade parece adquirir a consciência de que a riqueza material e a abundância tem limites. Não se trata 
mais de uma perspectiva futura, de um mundo que ainda correrá perigo; implica dizer, em outras palavras, que para o mercado e para a sociedade humana, o futuro já chegou com ameaças concretas.

Todo esse substrato confere sentido a uma premissa de eticidade comprometida com ações de responsabilidade social por parte das empresas o que converge, em termos de sistematização da ordem jurídica, para a configuração de uma obrigação de preservar atividades e comportamentos relevantes na defesa dos interesses da pessoa e da vida social.

\subsection{Responsabilidade social das empresas, ISO 26000 e evolução social no Brasil}

Como os efeitos jurídicos não podem estar dissociados da realidade social em que inseridos, acaba sendo necessário avaliar os efeitos sociais das ações de responsabilidade social das empresas; não é o caso de operar a distinção entre efeitos jurídicos e efeitos sociais, na esteira de uma separação entre ser e dever-se, no estilo do pensamento normativista; ao contrário, trata-se de identificar os contornos de uma normatividade material capaz de desdobrar aberturas de evolução social. Ou seja, por meio dos desdobramento de normatividade material, é que se torna possível estabelecer o compromisso de ações de responsabilidade social com a evolução da vida social, tomado aqui no sentido de uma ampliação de horizontes em que essas ações deixem de estar restritas a assegurar a imagem das empresas nos mercados.

No contexto de crescente regulamentação da atividade empresarial nos mercados, a ISO 26000 pode ser considerada norma internacional que disciplina as ações de responsabilidade social das empresas; essa norma tem como objetivo traçar diretrizes para ajudar empresas de diferentes portes, origens e localidades na implantação e desenvolvimento de políticas voltadas para a sustentabilidade organizadas nos seguintes eixos: governança organizacional, direitos humanos, práticas de trabalho, meio ambiente, práticas leais de operações, proteção do consumidor e envolvimento com a comunidade (ABNT NBR ISO 26000:2010; Deus; Seles; Vieira, 2014. p. 793-809). A norma ISO constitui espécie de guia de gestão empresarial comprometida com ações de responsabilidade social; não se trata, obviamente, de uma regulação jurídica específica de ações de responsabilidade social por parte das empresas.

A regulação das normas ISO foi objeto de estudo de Carla Barusso M. Haesbaert para quem esse sistema decorre da mudança de paradigma da economia globalizada, que passa a operar por meio de flexibilização da legislação de origem estatal e de autorregulamentação das 
práticas de mercado; Segundo Carla Barusso M. Haesbaert, as normas ISO incorporam uma dinâmica de igualdade de procedimentos e de técnicas, cujo objetivo é assegurar a qualidade de produtos e serviços no mercado. Mas o que é mais relevante para a análise acerca do compromisso das ações de responsabilidade social das empresas é que Carla Barusso M. Haesbaert sustenta que as normas ISO incorporam-se às práticas e costumes na atividade empresarial e, desse modo, passam a regular a atuação do mercado (2008). Nesse sentido, uma vez adotada uma gestão empresarial segundo as regras da ISO 26000, a empresa estaria incorporando ações de responsabilidade social que acabam conformado o modo como ela atua no mercado e, de uma forma mais ampla, do modo como se configura o próprio mercado. Assim, a ISO 26000 contempla o potencial de alterar a atuação das empresas no mercado, a partir da prática de ações de responsabilidade social. Contudo, como se trata de espécie de autorregulamentação, a princípio, as empresas não estão obrigadas a adotar a certificação da ISO 26000; a adoção da certificação ISO 26000 dependerá de um arranjo na atuação da empresa, já que o sistema implica uma ação coordenada de todos os agentes participantes de um determinado mercado. Resulta que a certificação ISO 26000 não incorpora um compromisso com a evolução social, na medida em que ela depende de uma ação coordenada de empresas nos mercados; ou seja, é necessário que o mercado como um todo esteja comprometido com ações de responsabilidade social; essa perspectiva, contudo, não se revela factível em determinados mercados com compromissos estreitos com a concorrência, a competição em escala globalizada, e com formas oligopolizadas de atuação. Para ser factível, a implementação da autorregulamentação proposta pela ISO 26000 em larga escala seria necessário alterar a lógica de funcionamento dos mercados no modelo de economia neoliberal da atualidade.

Tem-se então que as normas ISO, assim como a autorregulamentação, podem não ser suficientes para assegurar um compromisso por parte das empresas com ações de responsabilidade social, capazes de assegurar a evolução social.

Diante dessa limitação, resta avaliar o modo como se estrutura uma eticidade capaz de fazer a ligação efetiva entre ações de responsabilidade social das empresas e a evolução da vida em sociedade tomando como base a sociedade brasileira. Para essa finalidade é necessário ter em conta uma concepção de evolução social como abertura de possibilidades de mudanças significativas. Pode ser o caso de tomar como premissa a ideia de evolução social sugerida por Jürgen Habermas, definida em termos de processo de diferenciação de racionalidade e de complexidade sistêmica; enquanto aumenta a racionalidade do mundo da vida, cresce paralelamente a complexidade sistêmica $(2012,2)$. Desse modo, segundo Jürgen Habermas, o 
mundo da vida tem um dimensão fenomenológica e existencial e aparece como horizonte formador de contextos para processos de entendimento; as pessoas agem comunicativamente para localizar a si mesmas e às suas manifestações em espaços sociais e épocas históricas (2012, 2, p. 249). Na relação com o processo de diferenciação sistêmica, o mundo da vida constituiria o espaço na sociedade em que a pessoa pode adquirir e preservar a consciência do modo como a sua ação no mundo adquire sentido. Do ponto de vista da evolução social, que confronta perspectivas normativas e sistêmicas, pode-se dizer que as ações de responsabilidade social das empresas se tornam relevantes na medida em que contribuem para potencializar a preservação da consciência e o espaço social comunicativo e intersubjetivo, ou seja, quando preservam a pessoa e sua relação com os demais em sociedade, em termos de liberdade social. Daí o sentido de uma eticidade que se estrutura no desdobramento da vida em sociedade que faz emergir ações de responsabilidade social por parte das empresas e a obrigação de preservá-las.

Uma rápida reconstrução normativa permite evidenciar o modo como opera a potencialidade de abertura para a evolução social; trata-se de estabelecer uma métrica com as possibilidades de ampliação de liberdade social. Coloca-se em consideração o quanto a estrutura empresarial da atual economia de mercado permitiu ampliar formas de liberdade social ao longo da história e de, consequentemente, servir de indicativo para o que pode vir a ocorrer no futuro.

Depois de afirmar que na economia de mercado o cálculo de benefícios substituiu atitudes morais na produção de bens, o que estaria de acordo com a máxima de que a empresa está organizada apenas para o objetivo de lucro, Axel Honneth busca apoio na sociologia da organizações, desde Hegel, Durkheim, Polanyi e Parsons, para afirmar que as decisões nos mercado são economicamente mais racionais quanto mais intensamente se valem de uma perspectiva de responsabilidade social; ele afirma que a eficiência econômica nas competências mediadas pelo mercado aumentam a medida em que tais competências estão limitadas previamente por regras de ações morais distintas de graus de coercibilidade; logo, diz ele, não é o caso de aceitar a premissa de que o mercado constitui um sistema sem normas; a liberdade de mercado está sujeita à conformação da liberdade social (2014, p. 250-253). E o que significa conformar ou realizar a liberdade social, nos termos do próprio Axel Honneth, diz respeito a assegurar uma espécie de liberdade em que ser livre se define pelo encontro com o outro mediante reconhecimento mútuo, no contexto de práticas institucionalizadas (2014, p. 68).

Verifica-se, desse modo, que as ações de responsabilidade social das empresas ganham relevância para a evolução social na medida em que elas estejam comprometidas com uma 
abertura que permita institucionalizar formas de reconhecimento e, com isso, possibilitar mudança social e ampliação de dignidade e de respeito para pessoas ou grupos de pessoas.

Nesse sentido, a métrica de reconstrução normativa permite avaliar o grau de compromisso da atividade empresarial com a evolução social. Considerada a realidade brasileira, pode-se dizer que a produção de bens mediada pelo mercado, apoiada na atividade empresarial, permitiu ampliar o acesso a educação e a saúde, reduzir índices de mortalidade infantil, assegurar renda mínima para pessoas na linha de pobreza extrema, além de um relativo avanço tecnológico subordinado à divisão do trabalho imposto pelas economias centrais. De todo modo, também persiste no Brasil a desigualdade de renda e de acesso a bens resultante da baixa remuneração do trabalho pelas empresas.

Assim, considerada a realidade brasileira, as ações de responsabilidade social das empresas que estejam comprometidas com as finalidades de evolução social precisam enfrentar a complexidade de assimetrias e desigualdades que configuram a estrutura da sociedade no Brasil. Trata-se de contribuir para superar desigualdades e ampliar possibilidades de liberdade social; em última análise, o que as ações de responsabilidade social das empresas devem assumir é um compromisso com a tarefa de inclusão de pessoas.

\section{CONCLUSÃO}

A análise se desenvolveu em um arco que se iniciou com a reconstrução histórica de práticas de responsabilidade social das empresas que, em determinado momento do desdobramento da economia de mercado na história, colocou a necessidade de precisão conceitual de efeitos sociais e jurídicos dessas ações. Tratou-se, portanto de objetivar uma passagem da prática ao conceito e sua repercussão jurídica.

Do ponto de vista jurídico, mostrou-se que as ações de responsabilidade social das empresas contemplam uma espécie de obrigação desprovida de ação que, todavia, não impede a configuração de uma exigibilidade que se revela em torno da necessidade de preservação de efeitos, no contexto da realidade, indispensáveis para a preservação de determinado grau e alcance de proteção da vida e da pessoa. Uma obrigação dessa natureza revela sua exigibilidade na medida em que compreendida a responsabilidade como inerente ao que é essencialmente humano.

A análise também deixou evidenciado que a normatividade que regula as ações de responsabilidade social não se estrutura unicamente por meio de iniciativas de autorregulamentação dos mercados. As normas ISO, por exemplo, podem não ser suficientes 
para estimular a prática de ações de responsabilidade social por parte das empresas. Ficou evidenciado que a potencialidade das ações de responsabilidade social das empresas depende do compromisso que se estrutura no interior da eticidade integrada ao desenvolvimento da vida em sociedade. Não se trata, portanto, de ações de responsabilidade social que denotem um compromisso unilateral, benevolente ou paternalista, de iniciativa das empresas; as ações de responsabilidade social das empresas estão inseridas no modo como se desdobram as necessidades de evolução social no desenvolvimento da economia de mercado.

Assim, em termos de síntese conclusiva, a análise mostra que as ações de responsabilidade social das empresas adquirem relevância a medida em que estão comprometidas com a evolução social e que um tal compromisso pode ser concretamente mensurado mediante a ampliação de formas de liberdade social.

De consequência, no que diz respeito à realidade social brasileira, as ações de responsabilidade social das empresas estão justificadas quando comprometidas, de forma efetiva, com a redução de desigualdades em todos os níveis, ou seja, com uma nova prática, que veio resultar da mediação conceitual e normativa, convergente com a sustentabilidade do mundo e da vida de todas as pessoas.

\section{REFERÊNCIAS}

ASHLEY, Patrícia Almeida (coord.). Ética e responsabilidade social nos negócios. 2. ed. São Paulo: Saraiva, 2005.

BERTONCINI, Mateus Eduardo Siqueira Nunes; MULLER, Ane Elize Deonara. O balanço social como instrumento jurídico da cidadania. Revista Jurídica - Unicuritiba. Curitiba: Centro Universitário Curitiba, vol n. ${ }^{\circ}$ 28, 2012, p. 465-485.

BESSA, Fabiane Lopes Bueno Netto. Responsabilidade social das empresas - práticas sociais e regulação jurídica. Rio de Janeiro: Lúmen Iuris, 2006.

DARCANCHY, Mara. (coord.). Direito, inclusão e responsabilidade social. São Paulo: LTr, 2013.

DEUS, Rafael Mattos de; SELES, Bruno Michel Roman Pais; VIEIRA, Karina Rabelo Ogasawara. As organizações e a ISO 26000: revisão dos conceitos, dos motivadores e das barreiras de implementação. Gest. Prod., São Carlos, v. 21, n. 4, p. 793-809, 2014.

ETHOS, Instituto. Glossário. Disponível em: https://www3.ethos.org.br/wpcontent/uploads/2013/09/Gloss\%C3\%A1rio-Indicadores-Ethos-V2013-09-022.pdf. Acesso em: 16 dez. 2016.

FRIEDMAN, Milton. A responsabilidade social das empresas é aumentar os seus lucros. The New York Times Magazine, 13 de setembro de 1970. Apud VEGA CASTRO-Sayán, 
Diego. Responsabilidad social empresarial, paternalismo y legislación. Revista de Economía y Derecho, [Sl], v. 6, n. 24, p. 117-131, junho 2014. ISSN 1729-7958. (Tradução e adaptação nossa).

Disponível

em:

[http://revistas.upc.edu.pe/index.php/economia/article/view/286]. Acesso em: 16 dez. 2016.

HABERMAS, Jürgen. Teoria do agir comunicativo - sobre a crítica da razão funcionalista. São Paulo: Martins Fontes, vol 2, 2012.

HAESBAERT, Carla Barusso M. Alcance das obrigações empresariais decorrentes das normas ISO. Dissertação de Mestrado. Centro Universitário Unicuritiba, Curitiba, 2008.

HEGEL, G.W.F. EI sistema de la eticidad. Madrid: Editora Nacional, 1982.

HONNETH, Axel. El derecho de la libertad - esbozo de una eticidad democrática. Madrid: Katz Editores, 2014.

JONAS, Hans. O princípio responsabilidade: ensaio de uma ética para a civilização tecnológica. Rio de Janeiro: Contraponto: PUC-Rio, 2006.

MORCELLI, Aier Tadeu; ÁVILA, Lucas Veiga. Responsabilidade social. Santa Maria: Universidade Federal de Santa Maria, Colégio Politécnico: Rede e-Tec Brasil, 2016.

NEVES, Ligia Alves; OLIVEIRA, Francisco Cardozo. O paradigma da justiça social como referencial teórico da responsabilidade social empresarial. Rio de Janeiro: Editora Clássica, 2012.

NORONHA, Fernando. Direito das obrigações. São Paulo: Editora Saraiva, 2010.

ORTOVÁ, Martina; STANKOVÁ, Eva. The preparedness of certain companies to implement the ISO 26000 standard. In: International Conference Liberec Economic Forum, 10., 2011, Liberec, Czech Republic. Liberec: Technická Univerzita v Liberci, 2011.

SEN, Amartya; KLIKSBERG, Bernardo. As pessoas em primeiro lugar: a ética do desenvolvimento e os problemas do mundo globalizado. São Paulo: Companhia das Letras, 2010 .

SILVA, Marcos Alves; KNOERR, Viviane Coelho de Séllos. Responsabilidade social da empresa e subcidadania pautas para uma reflexão de índole constitucional. Revista Jurídica Unicuritiba. Curitiba: Centro Universitário Curitiba, 2013, vol. 2, n. ${ }^{\circ}$ 31, p. 435-453.

SOUZA, Carlos Aurélio Mota de. (org.). Responsabilidade social das empresas. Juarez de Oliveira: São Paulo, 2007.

SOUZA-LIMA, José Edmilson, MACIEL-LIMA, Sandra. Responsabilidade social. A arte de cuidar do outro. Curitiba: Instituto Memória, 2014.

TOFFLER, Alvin. A terceira onda. 18. ed. (Trad. de João Távora). Rio de Janeiro: Record, 1992. 